\title{
Local leptin production in osteoarthritis subchondral osteoblasts may be responsible for their abnormal phenotypic expression
}

\author{
Marie-Solange Mutabaruka ${ }^{+1}$, Mohamed Aoulad Aissa ${ }^{+1}$, Aline Delalandre1, Martin Lavigne ${ }^{2}$ and Daniel Lajeunesse ${ }^{* 1}$
}

\begin{abstract}
Introduction: Leptin is a peptide hormone with a role in bone metabolism and rheumatic diseases. The subchondral bone tissue plays a prominent role in the pathophysiology of osteoarthritis $(\mathrm{OA})$, related to abnormal osteoblast (Ob) differentiation. Although leptin promotes the differentiation of $\mathrm{Ob}$ under normal conditions, a role for leptin in $\mathrm{OA} \mathrm{Ob}$ has not been demonstrated. Here we determined if endogenous leptin produced by OA Ob could be responsible for the expression of the abnormal phenotypic biomarkers observed in $\mathrm{OA} \mathrm{Ob}$.

Methods: We prepared primary normal and OA Ob from subchondral bone of tibial plateaus removed for knee surgery of OA patients or at autopsy. We determined the production of leptin and of the long, biologically active, leptin receptors (OB-Rb) using reverse transcriptase-polymerase chain reaction, ELISA and Western blot analysis. We determined the effect of leptin on cell proliferation by BrdU incorporation and 3-(4,5-Dimethylthiazol-2-yl)-2,5diphenyltetrazolium bromide (MTT) assays, and we determined by Western blot analysis phospho 42/44 MAPK (p42/44 Erk1/2) and phospho p38 levels. We then determined the effect of the addition of exogenous leptin, leptin receptor antagonists, inhibitors of leptin signaling or siRNA techniques on the phenotypic features of OA Ob. Phenotypic features of $\mathrm{Ob}$ were determined by measuring alkaline phosphatase activity (ALP), osteocalcin release (OC), collagen type 1 production (CICP) and of Transforming Growth Factor- $\beta 1$ (TGF- $\beta 1$ ).
\end{abstract}

Results: Leptin expression was increased approximately five-fold and protein levels approximately two-fold in $\mathrm{OA} O \mathrm{Ob}$ compared to normal. Leptin stimulated its own expression and the expression of OB-Rb in OA Ob. Leptin dosedependently stimulated cell proliferation of $\mathrm{OA} O \mathrm{Ob}$ and also increased phosphorylated p42/44 Erk1/2 and p38 levels. Inactivating antibodies against leptin reduced ALP, OC, CICP and TGF- $\beta 1$ levels in OA Ob. Tyrphostin (AG490) and piceatannol (Pce), inhibitors of leptin signaling, reproduced this effect. Inhibition of endogenous leptin levels using siRNA for leptin or inhibiting leptin signaling using siRNA for OB-Rb expression both reduced ALP and OC about $60 \%$. Exogenous leptin addition stimulated ALP, yet this failed to further increase OC or CICP.

Conclusions: These results suggest that abnormal production of leptin by OA Ob could be responsible, in part, for the elevated levels of ALP, OC, collagen type 1 and TGF- $\beta 1$ observed in these cells compared to normal. Leptin also stimulated cell proliferation, and Erk $1 / 2$ and p38 signaling. Taken together, these data suggest leptin could contribute to abnormal osteoblast function in $\mathrm{OA}$.

\section{Introduction}

Osteoarthritis is characterized by progressive articular cartilage loss, appositional new bone formation and sclerosis of the subchondral trabeculae and growth plate, formation of

\footnotetext{
* Correspondence: daniel.lajeunesse@umontreal.ca

1 Unité de recherche en Arthose, Centre de recherche du Centre Hospitalier de I'Université de Montréal (CR-CHUM), Hôpital Notre-Dame, 1560 rue Sherbrooke Est, Montréal, QC H2L 4 M1, Canada

+ Contributed equally
}

osteophytes, and an imbalance between loss of cartilage, due to matrix degradation, and an attempt to repair this matrix $[1,2]$. Synovitis is often observed and is considered to be secondary to the changes in hard tissues within the joint. Despite major progress in the last few years, we still have a lot to learn about the etiology, pathogenesis and progression of this disease [3]. The slowly progressive and multifactorial nature of the disease, its cyclical course, 
where a period of active disease is followed by a period of remission, have limited our comprehension of OA. Risks factors for this disease in humans include age, gender, genetic predisposition, mechanical stress and/or joint trauma, and obesity $[3,4]$.

A relationship exists between obesity/fat mass and bone mass, while the mechanisms responsible for this are still not fully understood, and OA patients have a better preserved bone mass [5,6], independently of body weight [7], than healthy individuals. High body mass index (BMI) and increased bone mineral density (BMD) suggest new bone synthesis exceeds degradation in OA. In support of this hypothesis, osteocalcin (a marker of bone formation) in synovial fluid and serum osteopontin (a bone specific matrix protein) were significantly higher in patients with knee scan abnormalities [8]. Gevers and Dequeker showed elevated serum osteocalcin levels in women with hand osteoarthritis, and elevated osteocalcin in cortical bone explants [9]. This group also reported that IGF-I and II, and TGF- $\beta$ levels are higher in samples of iliac crest bone of patients with OA [10], at a site distant from weight bearing joints, suggesting a generalized bone metabolic dysfunction. Our group showed that in vitro $\mathrm{OA} \mathrm{Ob}$ produced higher IGF-1 and TGF- $\beta$ levels compared to normal $[11,12]$.

Leptin, the product of the obese $(o b)$ gene, is a $16-\mathrm{kDa}$ secreted protein that is produced by white adipocytes and placenta, and functions as an afferent signal to influence energy homeostasis through effects on energy intake and expenditure [13-15]. When leptin is mutated it results in obesity in the ob/ob mouse [13]. It is now evident that leptin is also expressed in osteoblasts [16]. Moreover, in addition to its effects on the central nervous system (CNS), leptin acts through high affinity leptin receptors on cells in peripheral tissues [17-19]. Leptin suppresses specific biochemical processes contributing to lipid accumulation and adipocyte differentiation [20]. The long, signaling-competent isoform of the leptin receptor (OB-Rb) shows high expression peaks in the feeding centers of the hypothalamus [21], consistent with leptin being the afferent signal informing the CNS of the body fat status. However, obese people often have elevated leptin levels with limited effects of leptin administration. This is likely due to desensitization, via the saturable transport of leptin across the blood-brain barrier and abnormalities at the level of OB-Rb activation and/ or signal transduction [22].

The primary role of leptin in metabolic homeostasis is to provide to the hypothalamus the information on the amount of body fat, thereby modulating central nervous system functions that regulate food intake and energy balance $[23,24]$. Solely via this neuroendocrine loop, leptin was believed to control bone mass. For example, in obese children, an increase in height velocity is concomitant with acceleration of bone epiphyseal maturation of the growth plate [25] and leptin levels are increased and correlate positively with fat mass [26]. Hence, leptin was believed to be the neuroendocrine link between fat and bone mass [27-29]. Indeed, leptin increases the release of osteocalcin, an osteoblast-specific protein, via a hypothalamic relay [30]. Moreover, in fetal mice leptin increases growth of primary ossification centers [31], and leptin modulates osteogenesis $[29,32,33]$. Recent data also indicate that locally produced leptin may be more important than circulating leptin in regulation of bone metabolism [16,17,29], while body mass influences cortical bone mass independent of leptin signaling [34]. Leptin administration to a natural leptin knockout mouse model (ob/ob) increases bone mineral density (BMD) as well as limb length [35]. This positive effect on bone turnover may be linked to its effect on both IL- 6 and the osteoprotegerin (OPG)/RANKL system $[33,36]$. Leptin enhances metabolic markers in osteoblasts namely alkaline phosphatase activity, osteocalcin, Coll $1 \alpha 1$ chains, Insulinlike Growth factor- 1 and Transforming Growth Factor- $\beta 1$ (TGF- $\beta 1$ ) levels by approximately $40 \%$ [36], parameters which we previously showed to be all increased in $\mathrm{OA} \mathrm{Ob}$ compared to normal $[11,12]$.

Leptin was found by immunohistochemistry in OA cartilage and in osteophytes, while few staining could be found in normal tissues [37], and leptin levels correlated with cartilage destruction. Moreover, differential expression of leptin and leptin receptor $\mathrm{Ob}-\mathrm{Rb}$ was also recently uncovered between minimally affected and advanced OA cartilage [38]. Synovial fluid leptin levels also correlate with the severity of OA [39]. However, there are at present no key data on the presence or role of leptin in osteoblasts from the subchondral bone tissue of normal or OA individuals. Hence, this study was aimed at: i) identifying the source of leptin in OA bone tissue by measuring leptin expression and release by normal and $\mathrm{OA} \mathrm{Ob}$; ii) determining if exogenous leptin could alter cell proliferation of $\mathrm{OA} \mathrm{Ob}$; and iii) evaluating if local leptin production is responsible for abnormal production of phenotypic markers in OA Ob.

\section{Materials and methods}

\section{Patients and clinical parameters}

Tibial plateaus were dissected away from the remaining cartilage and trabecular bone under sterile conditions from OA patients who had undergone total knee replacement surgery as previously described $[11,12,40]$. A total of 64 patients (aged $71.5 \pm 9.9$ years) classified as having OA according to the recognized clinical criteria of the American College of Rheumatology were included in this study [41]. OA grade ranged from moderate to severe in these patients. None of the patients had received medication that would interfere with bone metabolism, including corticosteroids, for six months before surgery. A total of 16 subchondral bone specimens of tibial plateaus from normal individuals (aged 62.2 \pm 18.9 years) were collected at 
autopsy within $12 \mathrm{~h}$ of death. These were used following the establishment that they had not been on any medication that could interfere with bone metabolism or had any bone metabolic disease. Individuals showing abnormal cartilage macroscopic changes and/or subchondral bone plate sclerosis were not included in the normal group. All human materials were acquired following a signed agreement by patients undergoing knee surgery or their relatives for the specimens collected at autopsy following the Centre Hospitalier de l'Université de Montréal (CHUM) ethical committee guidelines.

\section{Preparation of primary subchondral bone cell culture}

Isolation of subchondral bone plate and the cell cultures were prepared as we recently described [42]. At confluence, cells were passaged once at 25,000 cells $/ \mathrm{cm}^{2}$ and grown for five days in HamF12/DMEM media (Sigma-Aldrich, Oakville, Ontario, Canada) containing 10\% FBS before specific assays. These cells were incubated with the same media containing $0.5 \%$ FBS. After 24 hours of preconditioning, cells were incubated for either an additional 48 hours in HamF12/DMEM media containing 0.5\% FBS and the indicated treatments for the determination of phenotypic markers, or they were incubated for an additional 24 hours in the same media in presence or absence of increasing doses of leptin and the indicated treatments for the determination of the expression of leption or OB-Rb, or they were incubated for 15 minutes with increasing doses of leptin in preparation for Western blot analysis of p42/44 and p38. For the determiniation of phenotypic markers, cells were either treated with $1 \mu \mathrm{g} / \mathrm{ml}$ recombinant human leptin (rhleptin, Calbiochem, San Diego, California, USA), $10 \mu \mathrm{g} /$ $\mathrm{ml}$ recombinant human leptin $\mathrm{R} / \mathrm{Fc}$ chimera (R\&D Systems, Minneapolis, MN, USA) that neutralizes the activity of rhleptin, $100 \mu \mathrm{M}$ Tyrphostin (AG490, Sigma-Aldrich), $75 \mu \mathrm{M}$ piceatannol (Pce, Sigma-Aldrich), or the vehicle. Supernatants were collected at the end of the incubation and kept at $-80^{\circ} \mathrm{C}$ prior to assays. Cells were either prepared for SDS-PAGE separation or RT-PCR experiments. Cells prepared for SDS-PAGE separation were lysed with RIPA buffer $(50 \mathrm{mM}$ Tris $\mathrm{HCl} \mathrm{pH} 7.4,1 \%$ NP-40, $0.5 \%$ Nadeoxicholate, $0.1 \% \mathrm{SDS}, 150 \mathrm{mM} \mathrm{NaCl}$ with the following inhibitors: $10 \mu \mathrm{g} / \mathrm{ml}$ aprotinin, $10 \mu \mathrm{g} / \mathrm{ml}$ leupeptin, $10 \mu \mathrm{g} / \mathrm{ml}$ pepstatin, $10 \mu \mathrm{g} / \mathrm{ml}$ O-phenatroline, $1 \mathrm{mM} \mathrm{Na-orthovana-}$ date, $1 \mathrm{mM}$ DTT), and kept at $-80^{\circ} \mathrm{C}$ prior to assays. Protein determination was performed by the bicinchoninic acid method [43].

\section{Phenotypic characterization of human subchondral Ob cell cultures}

Phenotypic features of $\mathrm{Ob}$ were determined by evaluating $1,25(\mathrm{OH})_{2} \mathrm{D}_{3}$-dependent $(50 \mathrm{nM})$ alkaline phosphatase activity and osteocalcin release, and by measuring the release of the carboxy-terminal propeptide of collagen type
1 (CICP) in cells treated or not for their last 48 hours of culture with recombinant human leptin $\mathrm{R} / \mathrm{Fc}$ chimera to neutralize the activity of leptin, $100 \mu \mathrm{M}$ tyrphostin (AG490) or $75 \mu \mathrm{M}$ piceatannol (Pce), inhibitors of leptin signaling, or with siRNA directed against leptin or OB-Rb (see below). Alkaline phosphatase activity was determined on cell aliquots by substrate hydrolysis using p-nitrophenylphosphate (PNPP), and osteocalcin release was determined in cell supernatants using an EIA as previously described $[11,12]$. CICP was determined using a selective ELISA (Quidel Corporation, Cedarlane, Hornby, Ontario, Canada) in conditioned media from confluent $\mathrm{OA} \mathrm{Ob}$ incubated in HAMF12/DMEM media containing $0.5 \%$ bovine serum albumine (BSA). CICP release was then reported as ng per cellular proteins. Transforming growth factor- $\beta 1$ (TGF- $\beta 1$ ) was measured in supernatants using a highly specific Quantikine ELISA assay from R\&D Systems (Minneapolis, MN, USA). The sensitivity of the assay is $7 \mathrm{pg} / \mathrm{ml}$ and is a very specific assay that does not cross react with related cytokines/growth factors when tested at saturating concentrations. Cellular proliferation was assessed using two complementary approaches: the BrdU cell proliferation assay as described in the system's manual from Calbiochem (San Diego, California, USA) and MTT assay as described by Zhao et al[44]. Cells were plated at 10,000 cells $/ \mathrm{cm}^{2}$ in 96-well plates in Ham F12/DMEM media containing 10\% FBS. After overnight attachment, cells were fed Ham F12/ DMEM media containing $0.5 \%$ FBS for 24 hours prior to stimulation with or without increasing doses of recombinant human leptin as indicated for another 24 hours of incubation.

\section{RT-PCR assays}

For RT-PCR assays, total cellular RNA from normal and $\mathrm{OA} \mathrm{Ob}$ was extracted with the TRIzol ${ }^{\mathrm{TM}}$ reagent (Invitrogen, Burlington, Ontario, Canada) according to the manufacturer's specifications and treated with the RNA-free ${ }^{\mathrm{TM}}$ Dnase Treatment and Removal kit (Ambion, Austin, TX, USA) to ensure complete removal of chromosomal DNA. The RNA was quantitated using the RiboGreen RNA quantification kit (Molecular Probes, Eugene, OR, USA). The RT reactions were primed with random hexamers with $1 \mu \mathrm{g}$ of total RNA in a $100 \mu \mathrm{l}$ final reaction volume followed by PCR amplification as previously described [40] using 20 pmol of each specific PCR primers (see below). The amplification of all mRNA species was performed separately from GAPDH mRNA amplification to avoid substrate depletion. After amplification, DNA was analyzed on an agarose gel and visualized by ultraviolet detection.

Real-time quantification of leptin and GAPDH mRNA was performed in the GeneAmp 5700 Sequence Detection System (Applied Biosystems, Foster City, CA, USA) with the 2× Quantitect SYBR Green PCR Master Mix (Qiagen, Missisauga, Ontario, Canada) used according to the manu- 
facturer's specifications. Primers used were: 5'-GGCTTTGGCCCTATCTTTTC-3' (sense) and 5'GGATAAGGTCAGGATGGGGT-3' (antisense) for Lep1; 5'-CCTCATCAAGACAATTGTCACC-3' (sense) and 5'CAGCATGTCCTGCAGAGACC-3' (antisense) for Lep2; 5'-GCCAGAGACAACCCTTTGTTAAA-3' (sense) and 5'TGGAGAACTCTGATGTCCGTGAA-3' (antisense) for OB-Rb; 5'-CAGAACATCATCCCTGCCTCT-3' (sense) and 5'-GCTTGACAAAGTGGTCGTTGAG-3' (antisense) for GAPDH. Amplicons were 197, 376, 417 and 319 bp, respectively. In brief, $100 \mathrm{ng}$ of the cDNA obtained from the RT reactions were amplified in a total volume of $50 \mu \mathrm{l}$ consisting of $1 \times$ Master mix, uracil-N-glycosylase (UNG, 0.5 Unit, Epicentre Technologies, Madison, WI, USA) and the gene-specific primers which were added at a final concentration of $200 \mathrm{nM}$. The tubes were first incubated for two minutes at $50^{\circ} \mathrm{C}$ (UNG reaction), then at $95^{\circ} \mathrm{C}$ for 15 minutes (UNG inactivation and polymerase activation) followed by 40 cycles consisting each of denaturation $\left(94^{\circ} \mathrm{C}\right.$ for 15 seconds), annealing $\left(60^{\circ} \mathrm{C}\right.$ for 30 seconds $)$, extension $\left(72^{\circ} \mathrm{C}\right.$ for 30 seconds) and data acquisition $\left(77^{\circ} \mathrm{C}\right.$ for 15 seconds) steps. The data were collected and processed with the GeneAmp 5700 SDS software and given as threshold cycles $(\mathrm{Ct})$, corresponding to the PCR cycle at which an increase in reporter fluorescence above baseline signal can first be detected. When comparing normal and OA basal expression levels, the $\mathrm{Ct}$ were converted to the number of molecules and the values for each sample calculated as the ratio of the number of molecules of the target gene/number of molecules of GAPDH.

\section{Inhibition of leptin and OB-Rb expression using siRNA}

We used a siRNA technique to transiently inhibit leptin or $\mathrm{OB}-\mathrm{Rb}$ expression in OA Ob. SiRNA were obtained from Dharmacon (Lafayette, CO, USA) and we followed the manufacturer's directions for their preparation. Briefly, OA Ob were split at 100,000 cells/ml. Leptin or OB-Rb siRNA (a set of four different siRNA per gene) or scramble RNA (basal condition) was added to $\mathrm{OA} \mathrm{Ob}$ at a final concentration of $100 \mathrm{ng} / \mathrm{ml}$ with $6 \mu \mathrm{l} \mathrm{Hi-perfect} \mathrm{(Quiagen,} \mathrm{Missi-}$ sauga, ON, Canada) per $100 \mu 1$ total volume in BGJb media without serum for one hour on Day 0 and Day 3. Cells were then fed BGJb media with $10 \%$ FBS containing $50 \mathrm{nM}$ $1,25(\mathrm{OH})_{2} \mathrm{D}_{3}$ until Day 7 , with media changes every two days. Cells were harvested in either ALPase buffer to perform ALP and protein determination or in TRIzol to prepare for RT-PCR to detect changes in leptin and OB-Rb levels. Supernatants were kept for the determination of osteocalcin.

\section{Western immunoblotting}

The cell extracts were loaded on polyacrylamide gels and separated by sodium dodecyl sulfate-polyacrylamide gel electrophoresis (SDS-PAGE) under reducing condition
[45]. Loading of the protein was adjusted according to the cellular protein concentration of each specimen. The proteins were then electrophoretically transferred onto Polyvinylidene Fluoride (PVDF) membranes (Boehringer Mannheim, Penzberg, Germany), and immunoblotting was performed as described in the ECL Plus Western blotting detection system's manual (Amersham Pharmacia Biotech, Piscataway, NJ, USA). Rabbit anti-leptin receptor at a dilution of 1:1,000 (Cedarlane, Hornby, Ontario, Canada), rabbit anti-human actin at a dilution of 1:10,000 (SigmaAldrich), rabbit anti p42/44 at a dilution of 1:5,000 (Cell Signaling Technology, Beverly, MA, USA), rabbit antiphosphorylated p42/44 (Thr202/Tyr204) at a dilution of 1:5,000 (Cell Signaling Technology), rabbit anti p38 at a dilution of 1:2,000 (Cell Signaling Technology), and antiphosphorylated p38 at a dilution of 1:1,000 (Cell Signaling Technology) as primary antibodies, and goat anti-rabbit IgG as secondary antibodies at a dilution of 1:20,000 (Upstate Biotechnology, Lake Placid, NY, USA) were used for the assays.

Densitometry analysis of western blot films was performed on a Macintosh Mac OS 9.1 computer using the public domain NIH Image program developed at the U.S. National Institutes of Health with the Scion Image 1.63 program [46].

\section{Evaluation of leptin production}

Leptin was evaluated in Ob-conditioned media. Confluent $\mathrm{Ob}$ were cultured for $48 \mathrm{~h}$ in HAMF12/DMEM media containing $0.5 \% \mathrm{FBS}$. At the end of the incubation, their conditioned-media were concentrated five-fold using Amicon Ultra-4 filters (Ultracil-10 k, Millipore Corporation, Bedford, MA, USA) with a cutoff of $10 \mathrm{kDa}$. Samples were centrifuged at $1,000 \mathrm{~g}$ for 15 minutes at $4^{\circ} \mathrm{C}$. The concentrated conditioned media were then tested for leptin using a selective high sensitivity ELISA (R\&D Systems). The sensitivity of the assay was $7.8 \mathrm{pg} / \mathrm{ml}$ and the intra-assay precision is $3.2 \pm 0.2 \%$.

\section{Statistical analysis}

All quantitative data are expressed as mean \pm SEM. Statistical analysis was performed by an ANOVA analysis of variance for dose-response experiments, followed by adequate subtests when statistical significance was reached. A non parametric Mann-Whitney U statistical test was performed for all other experiments and $P$ values $<0.05$ were considered statistically significant.

\section{Results}

Expression and production of leptin in osteoblasts

We first questioned if human $\mathrm{OA}$ osteoblasts $(\mathrm{Ob})$ expressed leptin compared to normal $\mathrm{Ob}$ using real-time RT-PCR with two different set of primers, one described by Dumond et al[37] for rat samples and adapted to the human 
sequence, and the other by Gordeladze et al [16] for primary human osteoblasts. Using both sets of primers we detected leptin expression in $\mathrm{OA} \mathrm{Ob}$ (Figure 1A). We next evaluated if $\mathrm{OA} \mathrm{Ob}$ produced variable levels compared to normal $\mathrm{Ob}$. Using real-time RT-PCR we observed that OA Ob produced about approximately five-fold more leptin mRNA than normal Ob using one set of primers (Figure 1B). Since leptin has been shown to promote its own expression [47], we next determined if this could be the case in OA Ob. Indeed, leptin dose-dependently stimulated its own expression (Figure $1 \mathrm{C}$ ), yet this was also the case for OB-Rb expression (Figure 2B). As $\mathrm{Ob}$ expressed leptin, we next evaluated the capacity of $\mathrm{Ob}$ to synthesize leptin. As shown in Figure 1D, $\mathrm{OA} \mathrm{Ob}$ released about approximately two-fold more leptin than normal $\mathrm{Ob}$ under basal condition when measured using a very selective ELISA.

\section{Expression and production of leptin receptors in osteoblasts}

In order to determine if $\mathrm{OA} \mathrm{Ob}$ could respond to leptin, we next evaluated the presence of the long, signaling competent, form of the leptin receptor (OB-Rb). As shown in Figure $2 \mathrm{~A}$ using real-time RT-PCR, OA Ob expressed slightly less $\mathrm{OB}-\mathrm{Rb}$ than normal $\mathrm{Ob}$ although this did not reach significance. Exogenous leptin at high concentrations significantly stimulated $\mathrm{OB}-\mathrm{Rb}$ expression in $\mathrm{OA} \mathrm{Ob}$ (Figure 2B). In addition, $\mathrm{OB}-\mathrm{Rb}$ mRNA levels were increased by both TGF- $\beta 1$ and HGF in OA Ob (not illustrated), and this increased expression was reflected at the protein level by Western blot analysis (Figure 2C). Similar Western blot results were obtained with OA chondrocytes (not illustrated).

\section{Role of leptin in abnormal phenotypic features of ostearthritic osteoblasts}

Since OA Ob expressed both leptin and leptin receptors, we tested if these cells could respond to exogenous leptin and we first determined the effect of leptin on cell proliferation. Figure 3A and 3B show that leptin dose-dependently (1 ng/ $\mathrm{ml}$ to $10 \mu \mathrm{g} / \mathrm{ml}$ ) stimulated cell proliferation and this effect plateaued at $100 \mathrm{ng} / \mathrm{ml}$ leptin when assessing proliferation using BrdU incorporation or MTT assay respectively. We next evaluated if the effect of leptin on cell proliferation was via the Erk 1/2 MAPK pathway as we previously showed with insulin-like growth factor 1 [45]. Indeed, in response to exogenous leptin, phospho p42/44 MAPK levels rose (Figure 3C). This effect was again dose-dependent and also plateaued around $100 \mathrm{ng} / \mathrm{ml}$ (Figure 3D). In addition, we evaluated the role of leptin on the p38 pathway. Again, leptin dose-dependently stimulated phospho p38 levels (Figure 3E) and this effect was significant at doses as low as $1 \mu \mathrm{g} / \mathrm{ml}$ (Figure $3 \mathrm{~F}$ ).

Leptin influences the synthesis of phenotypic markers and inflammatory mediators in a number of cells and in par- ticular can increase phenotypic markers in primary human $\mathrm{Ob}$ [36]. Because $\mathrm{OA} \mathrm{Ob}$ responded to exogenous leptin, we then questioned if the endogenous elevated leptin production observed in $\mathrm{OA} \mathrm{Ob}$ could be responsible for the abnormal phenotypic markers of these cells. Hence, we measured alkaline phosphatase activity, osteocalcin release and the production of CICP under basal condition and in the presence leptin or of a recombinant human leptin $\mathrm{R} / \mathrm{Fc}$ chimera (anti-Rb) that neutralizes the activity of leptin. First, in preliminary assays we tested if exogenous leptin, the recombinant leptin $\mathrm{R} / \mathrm{Fc}$ chimera or the antagonist of leptin signaling AG490 would alter alkaline phosphatase activity in normal $\mathrm{Ob}$. Indeed, leptin addition to normal $\mathrm{Ob}$ stimulated vitamin $\mathrm{D}_{3}$-dependent alkaline phosphatase activity, however, neither anti-Rb nor AG490 had any effect on this activity (Figure 4A), indicating no cytotoxic effects of these treatments on normal $\mathrm{Ob}$. Hence, we next tested their effect on $\mathrm{OA} \mathrm{Ob}$ and compared it to basal levels of these phenotypic markers in normal $\mathrm{Ob}$ run in parallel. Here, the inhibition of leptin signaling in $\mathrm{OA} \mathrm{Ob}$ in response to $100 \mu \mathrm{M}$ AG490 or $75 \mu \mathrm{M}$ Pce, selective inhibitors of leptin intracellular signaling, reduced ALPase and CICP to values similar to normal $\mathrm{Ob}$ (Figure 4B and 4D), whereas the effect of these inhibitors on osteocalcin secretion could not be tested since they interfered with the EIA method. These inhibitors did not promote any significant cell death as assessed by total protein content and cell count by trypan blue exclusion (not illustrated). In addition, anti-Rb inhibited all these activities in $\mathrm{OA} \mathrm{Ob}$ (Figure 4B to 4D). We then questioned if exogenous leptin could promote these activities. The addition of exogenous leptin to $\mathrm{OA} \mathrm{Ob}$ enhanced vitamin $\mathrm{D}_{3}$-dependent alkaline phosphatase activity (Figure $4 \mathrm{~B}$ ) as in normal $\mathrm{Ob}$ (Figure 4A), but it failed to further stimulate osteocalcin release (Figure 4B) or collagen type 1 production (Figure 4C) above their already elevated values in $\mathrm{OA}$ Ob.

As another key feature of $\mathrm{OA} \mathrm{Ob}$ that distinguishes them from normal $\mathrm{Ob}$ is their enhanced production of TGF- $\beta 1$ [12], and because leptin has been shown to stimulate TGF$\beta 1$ synthesis in other cells, we evaluated if high levels of TGF- $\beta 1$ in OA Ob could be due to a response to endogenous leptin via a paracrine/autocrine stimulation. As shown in Figure 4E, TGF- $\beta 1$ levels in OA Ob were elevated compared to normal $\mathrm{Ob}$ and the presence of AG490 or Pce reduced by approximately $50 \%$ and approximately $60 \%$ the endogenous levels of TGF- $\beta 1$ in $\mathrm{OA} \mathrm{Ob}$, reducing them to near normal values.

Last, using siRNA techniques, we next evaluated if inhibiting leptin or $\mathrm{OB}-\mathrm{Rb}$ would abrogate the response of $\mathrm{OA}$ $\mathrm{Ob}$ to endogenous leptin production. Indeed, as shown in Figure 5A, siRNA against leptin reduced alkaline phosphatase activity about $60 \%$ compared to a scrambled RNA. A similar observation could be made for osteocalcin (Figure 5B). Likewise, inhibiting $\mathrm{OB}-\mathrm{Rb}$ expression using 
A

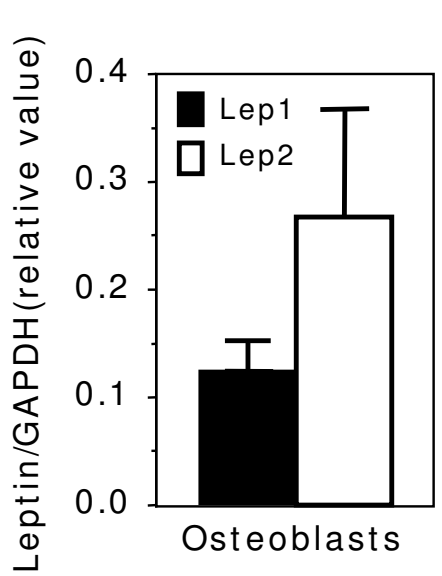

B

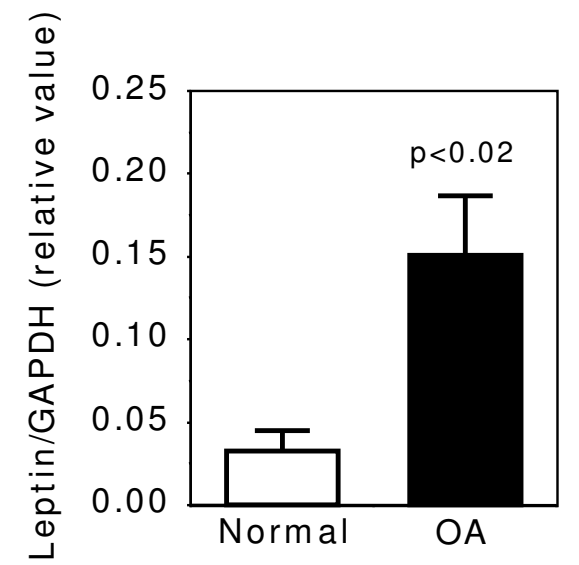

C

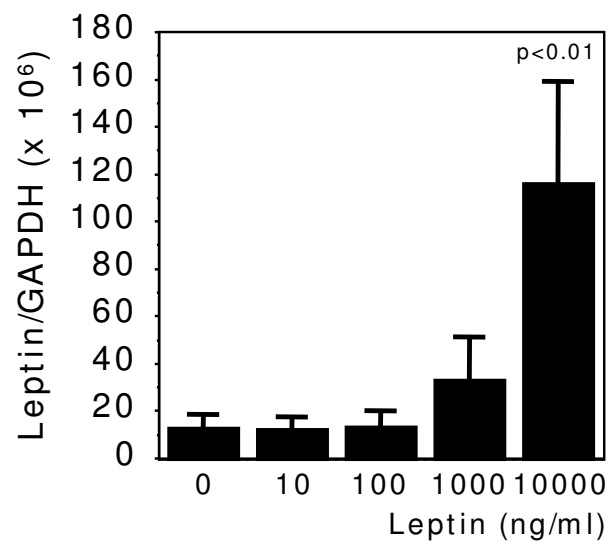

D

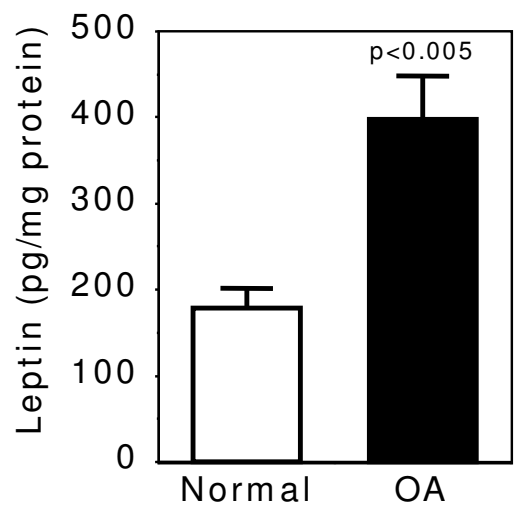

Figure 1 Production of leptin in normal and OA osteoblasts. The expression of leptin was first determined by qPCR. Confluent osteoblasts (Ob) were lized in TRIzol and RNA extracted as described in Material and methods. RNA (1 $\mu \mathrm{g})$ was reversed transcribed followed by qPCR amplification of 100 ng cDNA using specific primers for leptin and GAPDH. The data were processed with the GeneAmp 5700 SDS software and given as threshold cycle (Ct), corresponding to the PCR cycle at which an increase in reporter fluorescence above baseline signal can first be detected. The Ct was converted to the number of molecules and the values for each sample calculated as the ratio of the number of molecules of the target gene/number of molecules of GAPDH. A) Quantification of leptin mRNA using Lep1 and Lep2 primers. Results are given as the mean value of markers relative to GAPDH \pm SEM of $n=4$ OA preparations. B) Quantification of leptin mRNA levels in normal and OA Ob using Lep1 primers. Results are the mean \pm SEM of $n=$ 5 normal and $n=15$ OA individual Ob preparations. C) OA Ob were exposed to increasing doses of leptin and lepin mRNA levels were determined using Lep1 primers. Results are the mean \pm SEM of $n=4$ preparations. The protein production of leptin was next detected using a very selective ELISA. Conditioned-media of confluent normal and OA Ob incubated in HAM's F12/DMEM media containing 0.5\% FBS for their last 48 hours of culture were recuperated and stored at $-80^{\circ} \mathrm{C}$. D) Aliquots were taken to measure leptin using a very sensitive ELISA. Results are the mean \pm SEM of $n=5$ normal and $n=6$ OA individual Ob preparations.

siRNA techniques also reduced ALP and OC about $60 \%$ in $\mathrm{OA} \mathrm{Ob}$ (Figure 5A and 5B). Figures 5C and 5D show that specific siRNA inhibition reduced leptin and OB-Rb expression 60 and 55\% respectively in these cells compared to a scrambled RNA.

\section{Discussion}

In recent years, a key role of leptin in OA has been proposed, primarily based on the observation that human articular cartilage from OA patients showed elevated leptin levels using immunohistochemistry [37,38]. Leptin was previously known to be present in chondrocytes of the growth plate in young animals [27] and in fetal mice [39] yet this information was lacking in adult cartilage until Dumond et al [37] and Simopoulou et al described differential expression of both leptin and leptin receptors between normal and OA cartilage [38]. In the present study, we show that subchondral osteoblasts also have high levels of expression for leptin. Together with the study by Simopoulou et al[38], this could suggest that the presence of leptin in articular cartilage could also be due, at least in part, to its local production in subchondral bone tissue. Indeed, since $\mathrm{OA} \mathrm{Ob}$ expressed more leptin mRNA and produced more leptin, this could explain the higher protein levels found in 
A

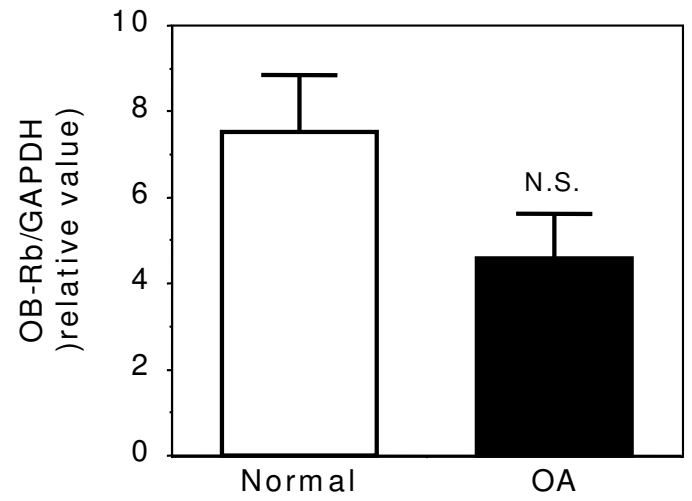

B

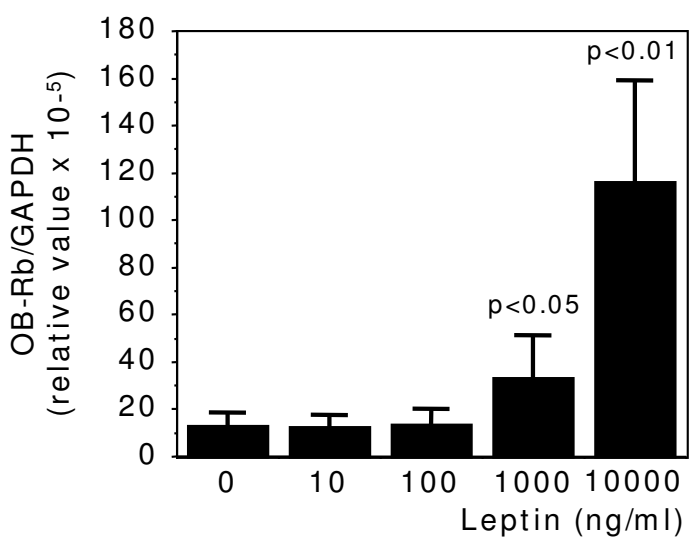

C

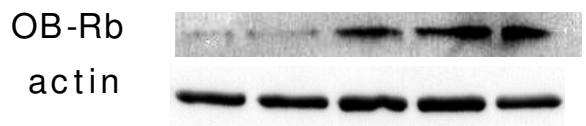

Figure 2 Production of leptin receptors (OB-Rb) in normal and $O A$ osteoblasts. The expression of leptin receptors was first determined by qPCR. A) Confluent Ob were lized in TRIzol and RNA extracted as described in Material and Methods. RNA was reversed transcribed followed by PCR amplification of $100 \mathrm{ng}$ CDNA as described in Figure 1 using OB-Rb and GAPDH primers. Results are the mean \pm SEM of $n=7$ normal and $n=19$ OA Ob preparations, $P<0.004$ vs normal and OA. B) $\mathrm{OA}$ Ob were incubated for 24 hours with increasing concentrations of exogenous leptin. Cells were then lyzed and used for PCR amplification of OB-Rb as in A. Results are the mean \pm SEM of $n=6 \mathrm{OA}$ Ob preparations. Second, the production of leptin receptors was determined by Western blot analysis. C) Confluent Ob were treated for 48 hours with or without $1,25(\mathrm{OH})_{2} \mathrm{D}_{3}(50 \mathrm{nM})$, leptin $(100 \mathrm{ng} / \mathrm{ml})$, TGF- $\beta 1$ (10 ng/ml) or HGF (10 ng/ml). The cells were then lized in RIPA buffer prior to separation using SDS-PAGE and Western blotting using specific antibodies to OB-Rb.

OA cartilage compared to normal tissue [37] if leptin can seep to the articular cartilage via either the enhanced microcirculation present in the subchondral bone plate and the deep layer of the articular cartilage or via microcracks $[48,49]$.
Our study also provided contrasting data on the regulation of leptin expression by OA Ob. We first tried to demonstrate a possible link between elevated TGF- $\beta 1$ and HGF levels produced by $\mathrm{OA} \mathrm{Ob}[12,50]$. and the expression of leptin by these cells. As previously showed for a number of tissues [51], TGF- $\beta 1$ reduced significantly the expression of leptin mRNA by $\mathrm{OA} \mathrm{Ob}$ (not illustrated). In contrast, HGF was without any significant effect on leptin expression. Second, $1,25(\mathrm{OH})_{2} \mathrm{D}_{3}$ stimulated several fold leptin expression by $\mathrm{OA} \mathrm{Ob}$. This is in sharp contrast to available data with adipocytes [52] that show a powerful inhibition of leptin expression in response to $1,25(\mathrm{OH})_{2} \mathrm{D}_{3}$. Hence, adipocytes and $\mathrm{Ob}$ behave differently and this could be a crucial step in $\mathrm{OA} \mathrm{Ob}$. Indeed, $\mathrm{OA} \mathrm{Ob}$ show enhanced responses to $1,25(\mathrm{OH})_{2} \mathrm{D}_{3}$ stimulation $[11,40]$, and this could possibly contribute to the enhanced expression of leptin.

Inasmuch as leptin expression is enhanced and its endogenous production is elevated in $\mathrm{OA} \mathrm{Ob}$, this could explain the slight reduction in OB-Rb expression in these cells compared to normal due to the continuous exposure to leptin. This reduction in $\mathrm{OB}-\mathrm{Rb}$ expression was also paralleled by a slight decrease of leptin receptors at the protein level as detected by Western blot analysis. However, $\mathrm{OA} \mathrm{Ob}$ could still respond to an acute exogenous leptin stimulation with an increase in OB-Rb expression. In addition, OB-Rb production was stimulated by TGF- $\beta 1$ and $\mathrm{HGF}$ in OA Ob, and this would indicate that the receptors could still be regulated normally in these cells. Nonetheless, this reduction in $\mathrm{OB}-\mathrm{Rb}$ does not lead to a reduction of the response of $\mathrm{OA} \mathrm{Ob}$ to leptin as was demonstrated here. Indeed, $\mathrm{OA} \mathrm{Ob}$ responded to exogenous addition of leptin with an increase in cell proliferation, phospho p42/44 MAPK, and in alkaline phosphatase activity as was previously reported for primary human osteoblasts [36]. In addition, leptin also stimulated phospho p38 levels in OA Ob in the present study downstream to a stimulation of the JAK2/STAT3 pathway (not illustrated). A previous study indicated a JAK/STAT dependent involvement of the p42/44 MAPK and p38 kinase pathways in the chondrogenic ATDC5 cell line in response to leptin stimulation [53]. In contrast, leptin could not increase osteocalcin secretion nor CICP or TGF$\beta 1$ levels in $\mathrm{OA} \mathrm{Ob}$. This could either indicate that alkaline phosphatase is more sensitive to leptin stimulation than the other markers or else that osteocalcin, CICP and TGF- $\beta 1$ production are less sensitive to leptin in these cells. Conversely, blocking OB- $\mathrm{Rb}$ signaling with inactivating antibodies reduced the production of alkaline phosphatase, osteocalcin, and CICP in OA Ob. This is a key observation since $\mathrm{OA} \mathrm{Ob}$ show abnormal phenotypic features, namely elevated alkaline phosphatase activity, osteocalcin release, collagen type 1 , IGF-1 and TGF- $\beta 1$ production $[11,12,40,54]$, all features that can be increased in response 


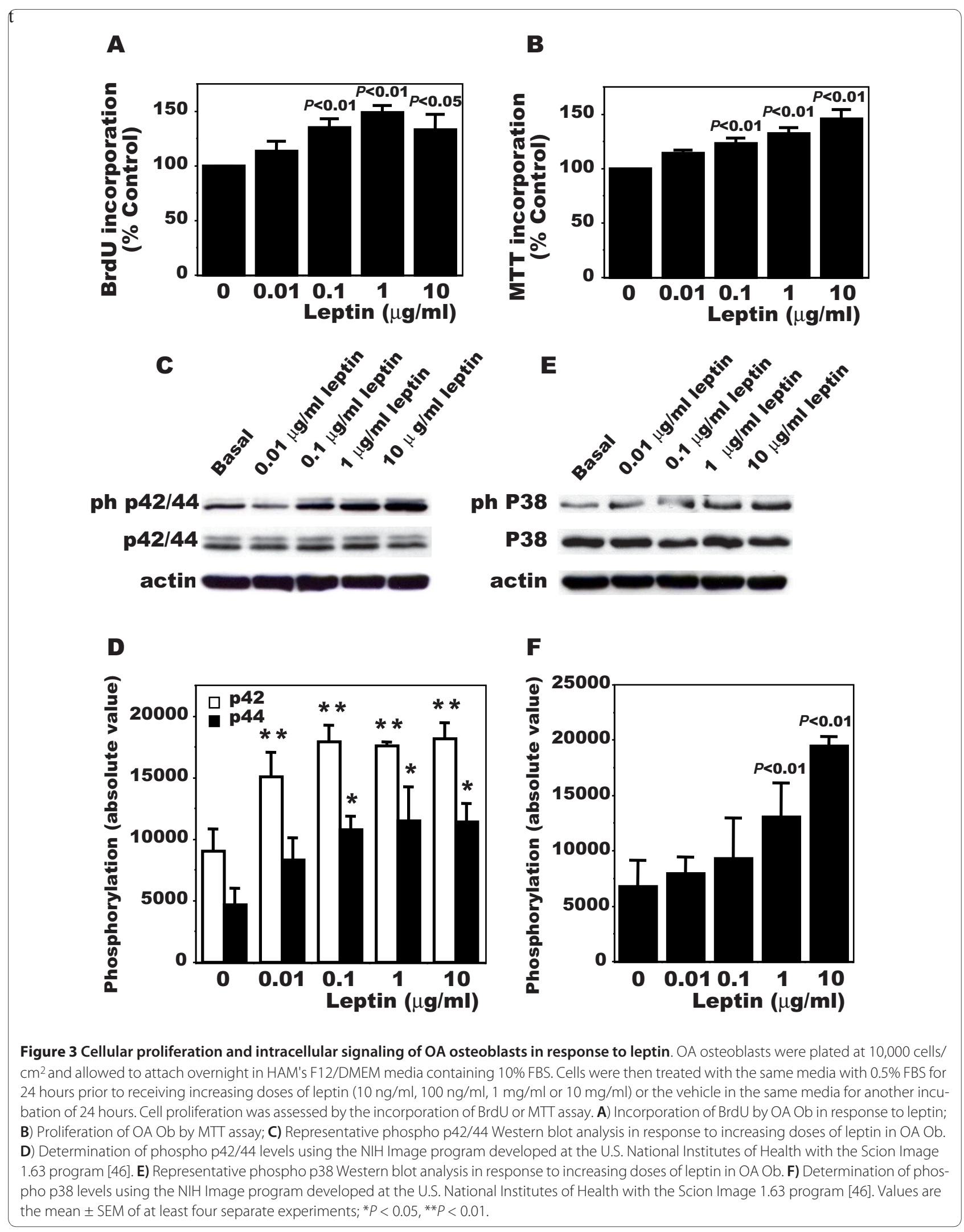




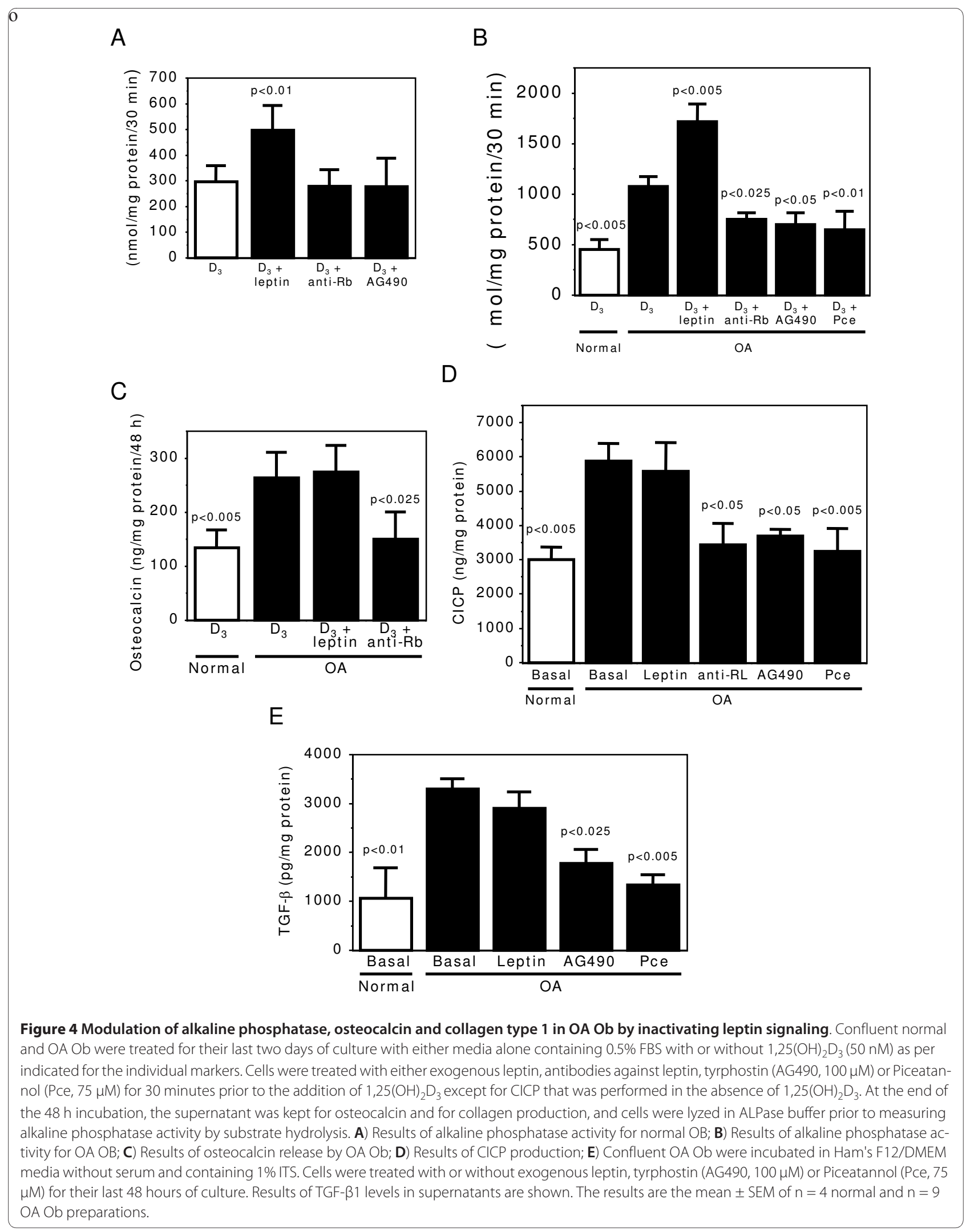


A

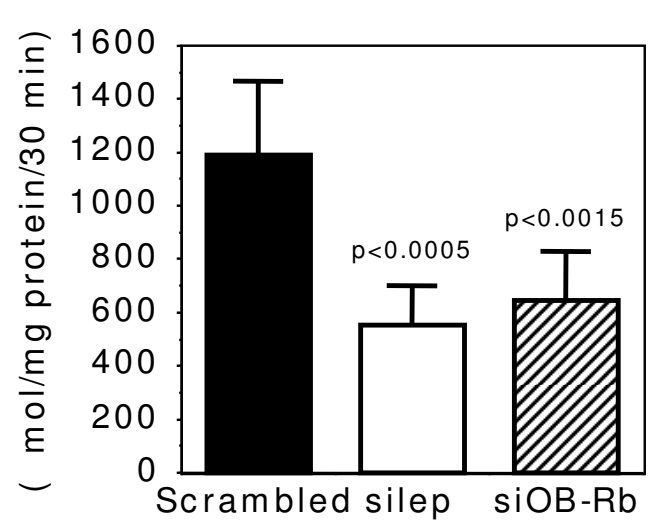

$\mathrm{B}$

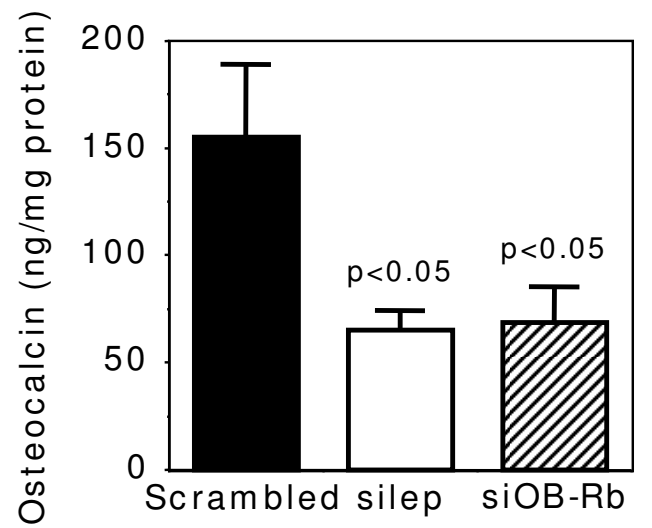

C

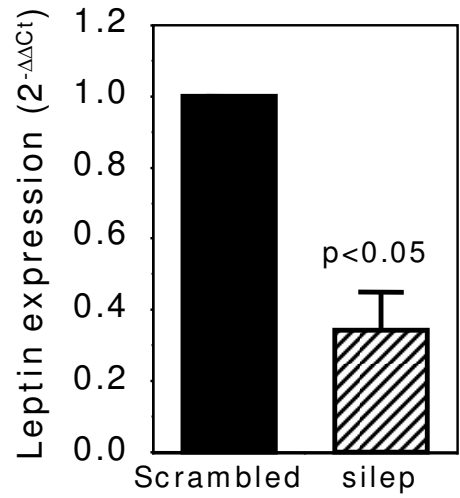

D

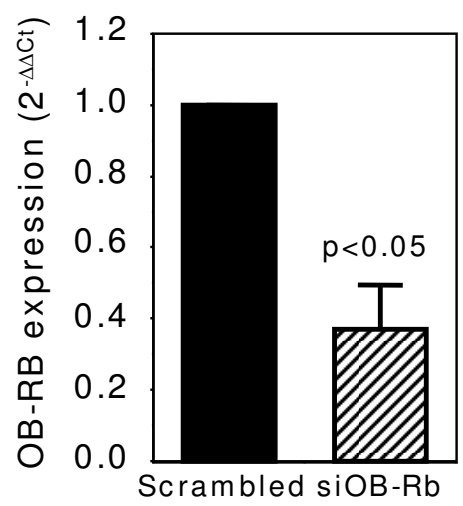

Figure 5 Modulation of alkaline phosphatase and osteocalcin release in OA Ob by inactivating leptin or leptin signaling. OA Ob were treated with siRNA for either leptin or OB-Rb or a scrambled RNA as described in Material and methods. Cells were then used to determine alkaline phosphatase activity and osteocalcin release. A) Results of alkaline phosphatase activity in response to leptin or OB-Rb siRNA treatments. B) Results of osteocalcin release in response to leptin or OB-Rb siRNA treatments. C) Leptin expression in response to siRNA. D) OB-Rb expression in response to siRNA. Results are the mean \pm SEM of $n=6$ OA Ob preparations.

leptin [36]. Last, tyrphostin and piceatannol, selective inhibitors respectively of the JAK2/STAT3 and JAK1/ STAT3 pathways involved in leptin signaling [55], reduced the activity of alkaline phosphatase, and the production of collagen type 1 and TGF- $\beta 1$ by OA Ob. Thus, these data suggest first, that the abnormal features of $\mathrm{OA} \mathrm{Ob}$ could be related to their endogenous elevated production of leptin, and second, that this response to leptin involves the JAK2/ STAT3 downstream MAPK targets, Erk1/2 and p38. Last, we showed a reduction in alkaline phosphatase activity and osteocalcin release by silencing leptin with siRNA or silencing $\mathrm{OB}-\mathrm{Rb}$ with siRNA in OA Ob. This again is pointing toward a key role of endogenous leptin to regulate these activities in $\mathrm{OA} \mathrm{Ob}$.
Inasmuch as leptin contributes to stimulate the production of IGF- 1 and TGF- $\beta 1$ by human osteoblasts [36], our data would also indicate that leptin is a key signal in OA pathophysiology. Indeed, both growth factors have been implicated in the initiation and/or progression of OA and we previously showed that both growth factors were elevated in in vitro subchondral osteoblasts isolated from OA patients $[12,56]$ Moreover, leptin can alter the signaling of IGF-1 in a number of cell systems [57-59] and we previously reported that IGF-1 signaling is abnormal in $\mathrm{OA} \mathrm{Ob}$ [45]. We also previously showed that HGF is not produced by chondrocytes but is produced in higher abundance by $\mathrm{OA} \mathrm{Ob}$ [50] whereas HGF can increase OB-Rb levels in chondrocytes (not illustrated). Hence, the presence of ele- 
vated levels of leptin $[37,38]$ in OA cartilage, and of elevated expression of $\mathrm{OB}-\mathrm{Rb}[38,60]$ possibly due to elevated HGF levels [50] derived from osteoblasts of the subchondral bone plate, could therefore promote the response to leptin in OA chondrocytes.

The failure of leptin to stimulate all markers of osteoblasts whereas inhibiting leptin signaling modified all parameters is puzzling. However, an abnormal response to leptin in $\mathrm{OA} \mathrm{Ob}$ is likely and resembles what we previously observed for the response to IGF-1. First, an increase in phospho-PTP1B/Syp may be crucial for leptin signaling as PTP1B/Syp controls STAT3 phosphorylation and its interaction with target genes, a key signaling pathway for leptin [61]. Since increased hypothalamic PTP1B levels can contribute to leptin resistance [62], our previous demonstration that PTP1B/Syp levels and phosphorylation are increased in $\mathrm{OA} \mathrm{Ob}$ [45] suggests that $\mathrm{OA} \mathrm{Ob}$ could actually be resistant to some, yet not all, leptin signaling since leptin did increase the phosphorylation of Erk $1 / 2$ and $\mathrm{p} 38$ in $\mathrm{OA} \mathrm{Ob}$ (our present data). Second, leptin promotes tyrosine phosphorylation of SHC proteins and the association of SHC with Grb2 in human embryonic cells HEK 293 [63], whereas we previously showed that Grb2 interaction with IRS-1 and SHC is abnormal in OA Ob [45]. Third, leptin can modulate its effects on human $\mathrm{Ob}$ via an inhibition of apoptosis [36], and we observed a reduction in Bax- $\alpha$ to $\mathrm{Bcl} 2$ expression in $\mathrm{OA} \mathrm{Ob}$ compared to normal $\mathrm{Ob}$ [45] an indication of reduced apoptosis. Indeed, leptin increases the proliferation of human osteoblast-like SaOS-2 cells via Erk1/2 [64], and we also showed that $\mathrm{OA} \mathrm{Ob}$ have an enhanced proliferation rate and increased phospho Erk 1/2 levels in response to leptin. Last, we showed that leptin stimulates alkaline phosphatase activity in OA Ob yet failed to stimulate any further osteocalcin release, collagen production or TGF- $\beta 1$ levels above their already elevated levels compared to normal $\mathrm{Ob}$, whereas inhibiting leptin signaling clearly showed an inhibition of all these parameters. Previous studies have shown that long term exposures to leptin are needed to modify the expression of collagen type 1 , TGF- $\beta 1$ and osteocalcin [36] whereas the inhibition of collagen synthesis with the JAK inhibitor AG490 (tyrphostin) is rapid [65] similar to what we observed here. Taken together, these data would suggest that a number of, yet not all, signaling pathways are altered in $\mathrm{OA} \mathrm{Ob}$ in response to leptin. Conversely, partners of leptin signaling may be abnormal in $\mathrm{OA} \mathrm{Ob}$ and this may stem from the possible abnormal cross-talk between the IGF-1 signaling, already abnormal in $\mathrm{OA} \mathrm{Ob} \mathrm{[45],} \mathrm{and} \mathrm{leptin} \mathrm{signaling} \mathrm{path-}$ ways in these cells. These hypotheses remain to be explored.

\section{Conclusions}

This study indicates that $\mathrm{OA} \mathrm{Ob}$ expressed and released more leptin than normal. This elevated production of leptin is responsible, at least in part, for the abnormally elevated levels of biomarkers of $\mathrm{OA} \mathrm{Ob}$ compared to normal, and to elevated production of TGF- $\beta 1$. Together, these data indicate a key role of leptin in OA pathophysiology.

\section{Abbreviations}

ALP: alkaline phosphatise; BMD: bone mineral density; BMI: body mass index; BSA: bovive serum albumin; CICP: collagen type 1 carboxyl terminal peptide; CNS: central nervous system; IGF-1: insulin-like growth factor 1; MTT: (3-(4,5Dimethylthiazol-2-yl)-2,5-diphenyltetrazolium bromide; OA: osteoarthritis; $\mathrm{Ob}$ : osteoblasts; OB-Rb: leptin receptor long form; OC: osteocalcin; OPG: osteoprotegerin; PCR: polymerase chain reaction; PNPP: para-nitrophenyl phosphate; PVDF: Polyvinylidene Fluoride; TGF- $\beta 1$ : transforming growth factor beta-1.

\section{Competing interests}

The authors declare that they have no competing interests.

\section{Authors' contributions}

MSM and MAA performed the experiments, participated in the statistical analysis and the interpretation of data, and drafted the manuscript. AD performed the experiments, participated in the statistical analysis and interpretation of data, and reviewed the manuscript. ML participated in the recruitment of OA patients, collection of samples, interpretation of data, and reviewed the manuscirpt. DL participated in the design of the study, performed the statistical analysis and the interpretation of data, and drafted the manuscript. All authors read and approved the final manuscript.

\section{Acknowledgements}

This study was supported by grants MOP-49501 from the Canadian Institutes for Health Research (CIHR) and TAS-0089 from the Arthritis Society of Canada/ CIHR to DL.

\section{Author Details}

UUnité de recherche en Arthose, Centre de recherche du Centre Hospitalier de I'Université de Montréal (CR-CHUM), Hôpital Notre-Dame, 1560 rue Sherbrooke Est, Montréal, QC H2L 4 M1, Canada and 2Chirurgie Orthopédique, Hôpital Maisonneuve-Rosemont, 5415 boul. I'Assomption, Montréal, QC H1T 2 M4, Canada

Received: 9 September 2009 Revisions Requested: 5 October 2009 Revised: 8 January 2010 Accepted: 8 February 2010 Published: February 2010

\section{References}

1. Poole AR: Cartilage in health and disease. In Arthritis and Allied Conditions: a Textbook of Rheumatology Edited by: Koopman WJ. Baltimore: Williams \& Wilkins; 1997:255-308

2. Hamerman D: The biology of osteoarthritis. N Engl J Med 1989, 320:1322-1330.

3. Davis MA: Epidemiology of osteoarthritis. Clin Geriatr Med 1988, 4:241-255.

4. Felson DT, Anderson JJ, Naimark A, Walker AM, Meenan RF: Obesity and knee osteoarthritis. Ann Intern Med 1988, 109:18-24.

5. Foss MVL, Byers PD: Bone density, osteoarthrosis of the hip and fracture of the upper end of the femur. Ann Rheum Dis 1972, 31:259-264.

6. Roh YS, Dequeker J, Muiler JC: Bone mass is osteoarthrosis, measured in vivo by photon absorption. J Bone Joint Surg Am 1974, 56:587-591.

7. Mokassa Bakumobatane L, Dequeker J, Raymaekers G, Aerssens J: Effects of osteoarthritis $(\mathrm{OA})$ and body weight on subchondral cancellous bone quality of proximal tibia. Osteoarthritis Cart 1993, 1:55-56.

8. Sharif M, George E, Dieppe PA: Correlation between synovial fluid markers of cartilage and bone turnover and scintigraphic scan abnormalities in osteoarthritis of the knee. Arthritis Rheum 1995, 38:78-81.

9. Gevers G, Dequeker J: Collagen and non-collagenous protein content (osteocalcin, sialoprotein, proteoglycan) in the iliac crest bone and serum osteocalcin in women with and without hand osteoarthritis. Coll Relat Res 1987, 7:435-442.

10. Dequeker J, Mohan R, Finkelman RD, Aerssens J, Baylink DJ: Generalized osteoarthritis associated with increased insulin-like growth factor 
types I and II and transforming growth factor beta in cortical bone from the iliac crest. Possible mechanism of increased bone density and protection against osteoporosis. Arthritis Rheum 1993, 36:1702-1708

11. Hilal G, Martel-Pelletier J, Pelletier JP, Ranger P, Lajeunesse D: Osteoblastlike cells from human subchondral osteoarthritic bone demonstrate an altered phenotype in vitro: Possible role in subchondral bone sclerosis. Arthritis Rheum 1998, 41:891-899.

12. Massicotte F, Lajeunesse D, Benderdour M, Pelletier J-P, Hilal G, Duval N, Martel-Pelletier J: Can altered production of interleukin $1 \beta$, interleukin6 , transforming growth factor- $\beta$ and prostaglandin E2 by isolated human subchondral osteoblasts identify two subgroups of osteoarthritic patients. Osteoarthritis Cartilage 2002, 10:491-500.

13. Zhang Y, Procenca R, Maffei M, Barone M, Leopold L, Friedman JM: Positional cloning of the mouse obese gene and its human homologue. Nature 1994, 372:425-432.

14. Campfield LA, Smith FJ, Guisez Y, Devos R, Burn P: Recombinant mouse OB-protein: evidence for a peripheral signal linking adiposity and central neural networks. Science 1995, 269:546-549.

15. Masuzaki M, Ogawa Y, Sagawa N, Hosoda K, Matsumoto T, Mise H, Nishimura H, Yoshimasa Y, Tanaka I, Mori T, Nakao K: Nonadipose tissue production of leptin: leptin as a novel placenta-derived hormone in humans. Nature Medicine 1997, 3:1029-1033.

16. Reseland JE, Syversen U, Bakke I, Qvigstad G, Eide LG, Hjertner O, Gordeladze JO, Drevon CA: Leptin is expressed in and secreted from primary cultures of human osteoblasts and promotes bone mineralization. J Bone Miner Res 2001, 16:1426-1433.

17. Lee YJ, Park JH, Ju SK, You KH, Ko JS, Kim HM: Leptin receptor isoform expression in rat osteoblasts and their functional analysis. FEBS Lett 2002, 528:43-47.

18. Gainsford T, Willson TA, Metcalf D, Handman E, McFarlane C, Ng A, Nicola NA, Alexander WS, Hilton DJ: Leptin can induce proliferation, differentiation, and functional activation of hematopoietic cells. Proc Natl Acad Sci U S A 1996, 93:14564-14568,

19. Siegrist-Kaiser CA, Pauli V, Juge-Aubry CE, Boss O, Pernin A, Chin WW, Cusin I, Rohner-Jeanrenaud F, Burger AG, Zapf J, Meier CA: Direct effects of leptin on brown and white adipose tissue. J Clin Invest 1997, 100:2858-2864

20. Shimabukuro M, Koyama K, Chen G, Wand MY, Trieu F, Lee Y, Newgard CB, Unger RH: Direct antidiabetic effect of leptin through triglyceride depletion of tissues. Proc Natl Acad Sci USA 1997, 94:4637-4641.

21. Tartaglia LA, Dembski M, Weng X, Deng N, Culpepper J, Devos R, Richards GJ, Campfield LA, Clark FT, Deeds J, Muir C, Sanker S, Moriarty A, Moore KJ, Smutko JS, Mays GG, Woolf EAMCA, Tepper RI: Identification and Expression Cloning of a Leptin Receptor, OB-R. Cell 1995, 83:1263-1271.

22. El-Haschimi K, Pierroz DD, Hileman SM, Bjorbaek C, Flier JS: Two defects contribute to hypothalamic leptin resistance in mice with diet-induced obesity. J Clin Invest 2000, 105:1827-1832.

23. Takeda S, Elefteriou F, Levasseur R, Liu X, Zhao L, Parker KL, Armstrong D, Ducy P, Karsenty G: Leptin regulates bone formation via the sympathetic nervous system. Cell 2002, 111:305-317.

24. Ducy P, Amling M, Takeda S, Prieme M, Schilling AF, Beil FT, Shen J, Vinson C, Rueger JM, Karsenty G: Leptin inhibits bone formation through a hypothalamic relay: A central control of bone mass. Cell 2000, 100:197-207.

25. Vignolo M, Naselli A, Di Battista E, Mostert M, Aicardi G: Growth and development in simple obesity. Eur J Pediatr 1988, 147:242-244.

26. Considine RV, Sinha MK, Heiman ML, Kriauciunas A, Stephens TW, Nyce MR, Ohannesian JP, Marco CC, McKee LJ, Bauer TL, Caro JF: Serum immunoreactive-leptin concentrations in normal-weight and obese humans. NEngl J Med 1996, 334:292-295.

27. Maor G, Rochwerger M, Segev Y, Phillip M: Leptin acts as a growth factor on the chondrocytes of skeletal growth centers. J Bone Miner Res 2002, 17:1034-1043.

28. Thomas T, Burguera B: Is leptin the link between fat and bone mass? J Bone Miner Res 2002, 17:1563-1569.

29. Reseland JE, Gordeladze JO: Role of leptin in bone growth: central player or peripheral supporter? FEBS Letters 2002, 528:40-42.

30. Kalra SP, Dube MG, Iwaniec UT: Leptin increases osteoblast-specific osteocalcin release through a hypothalamic relay. Peptides 2009, 30:967-973
31. Bertoni L, Ferretti M, Cavani F, Zavatti M, Resca E, Benelli A, Palumbo C: Leptin increases growth of primary ossification centers in fetal mice. J Anat 2009, 215:577-583.

32. Wlodarski K, Wlodarski P: Leptin as a modulator of osteogenesis. Ortop Traumatol Rehabil 2009, 11:1-6.

33. Gordeladze JO, Reseland JE: A unified model for the action of leptin on bone turnover. Journal of Cellular Biochemistry 2003, 88:706-712.

34. Iwaniec UT, Dube MG, Boghossian S, Song H, Helferich WG, Turner RT, Kalra SP: Body mass influences cortical bone mass independent of leptin signaling. Bone 2009, 44:404-412.

35. Steppan CM, Crawford DT, Chidsey-Frink KL, Ke HZ, Swick AG: Leptin is a potent stimulator of bone growth in ob/ob mice. Regulatory Peptides 2000, 92:73-78.

36. Gordeladze JO, Drevon CA, Syversen U, Reseland JE: Leptin stimulates human osteoblastic cell proliferation, de novo collagen synthesis, and mineralization: Impact on differentiation markers, apoptosis, and osteoclastic signaling. J Cell Biochem 2002, 85:825-836

37. Dumond H, Presle N, Terlain B, Mainard D, Loeuille D, Netter P, Pottie P. Evidence for a key role of leptin in osteoarthritis. Arthritis Rheum 2003, 48:3118-3129.

38. Simopoulou T, Malizos KN, lliopoulos D, Stefanou N, Papatheodorou L, loannou M, Tsezou A: Differential expression of leptin and leptin's receptor isoform $(\mathrm{Ob}-\mathrm{Rb})$ mRNA between advanced and minimally affected osteoarthritic cartilage; effect on cartilage metabolism. Osteoarthritis Cartilage 2007, 15:872-883.

39. Ku JH, Lee CK, Joo BS, An BM, Choi SH, Wang TH, Cho HL: Correlation of synovial fluid leptin concentrations with the severity of osteoarthritis. Clin Rheumatol 2009, 28:1431-1435.

40. Hilal G, Massicotte F, Martel-Pelletier J, Fernandes JC, Pelletier JP, Lajeunesse D: Endogenous prostaglandin E2 and insulin-like growth factor 1 can modulate the levels of parathyroid hormone receptor in human osteoarthritic osteoblasts. J Bone Miner Res 2001, 16:713-721.

41. Altman RD, Asch E, Bloch DA, Bole G, Borenstein D, Brandt KD, Christy W, Cooke TD, Greenwald R, Hochberg M, Howell DS, Kaplan D, Koopman W, Longley SI, Mankin HJ, McShane DJ, Medsger TA Jr, Meehan R, Mikkelsen W, Moskowitz RW, Murphy W, Rothschild B, Segal L, Sokoloff L, Wolfe F: Development of criteria for the classification and reporting of osteoarthritis. Classification of osteoarthritis of the knee. Arthritis Rheum 1986, 29:1039-1049.

42. Couchourel D, Aubry I, Delalandre A, Lavigne M, Martel-Pelletier J, Pelletier J-P, Lajeunesse D: Altered Mineralization of Human Osteoarthritic Osteoblasts is due to abnormal collagen type 1 production. Arthritis Rheum 2009, 60:1438-1450.

43. Smith PK, Krohn RI, Hermanson GT, Mallia AK, Gartner FH, Provenzano MD, Fujimoto EK, Goeke NM, Olson BJ, Klenk DC: Measurement of protein using Bicinchoninic Acid. Anal Biochem 1985, 150:76-85.

44. Zhao CQ, Liu D, Li H, Jiang LS, Dai LY: Expression of leptin and its functional receptor on disc cells: contribution to cell proliferation. Spine (Phila Pa 1976) 2008, 33:E858-864

45. Massicotte F, Aubry I, Martel-Pelletier J, Pelletier JP, Fernandes J, Lajeunesse D: Abnormal insulin-like growth factor 1 signaling in human osteoarthritic subchondral bone osteoblasts. Arthritis Res Ther 2006, 8:R177.

46. Research Services Branch (RSB): Public domain NIH Image program (developed at the U.S. National Institutes of Health). [http:// rsb.info.nih.gov/nih-image/

47. Wang J, Liu R, Liu L, Chowdhury R, Barzilai N, Tan J, Rossetti L: The effect of leptin on Lep expression is tissue-specific and nutritionnally regulated. Nat Med 1999, 5:895-899.

48. Imhof H, Breitenseher M, Kainberger F, Rand T, Trattnig S: Importance of subchondral bone to articular cartilage in health and disease. Top Magn Reson Imaging 1999, 10:180-192.

49. Sokoloff L: Microcracks in the calcified layer of articular cartilage. Arch Pathol Lab Med 1993, 117:191-195.

50. Guévremont M, Martel-Pelletier J, Massicotte F, Tardif G, Pelletier J-P, Ranger $P$, Lajeunesse D, Reboul P: Human adult chondrocytes express hepatocyte growth factor (HGF) isoforms but not HGF. Potential implication of osteoblasts for the HGF presence in cartilage. J Bone Miner Res 2003, 18:1073-1081.

51. Zhang F, Chen Y, Heiman M, Dimarchi R: Leptin: structure, function and biology. Vitam Horm 2005, 71:345-372. 
52. Menendez C, Lage M, Peino R, Baldelli R, Concheiro P, Dieguez C, Casanueva FF: Retinoic acid and vitamin D(3) powerfully inhibit in vitro leptin secretion by human adipose tissue. J Endocrinol 2001, 170:425-431.

53. Ben-Eliezer M, Phillip M, Gat-Yablonski G: Leptin regulates chondrogenic differentiation in ATDC5 cell-line through JAK/STAT and MAPK pathways. Endocrine 2007, 32:235-244.

54. Lisignoli G, Toneguzzi S, Piacentini A, Cristino S, Grassi F, Cavallo C, Facchini A: CXCL12 (SDF-1) and CXCL13 (BCA-1) chemokines significantly induce proliferation and collagen type I expression in osteoblasts from osteoarthritis patients. J Cell Physiol 2006, 206:78-85.

55. Kloek C, Haq AK, Dunn SL, Lavery HJ, Banks AS, Myers MG Jr: Regulation of Jak kinases by intracellular leptin receptor sequences. J Biol Chem 2002, 277:41547-41555.

56. Massicotte F, Fernandes JC, Martel-Pelletier J, Pelletier JP, Lajeunesse D: Modulation of insulin-like growth factor 1 levels in human osteoarthritic subchondral bone osteoblasts. Bone 2006, 38:333-341.

57. Cohen B, Novick D, Rubinstein M: Modulation of insulin activities by leptin. Science 1996, 274:1185-1188

58. Margetic S, Gazzola C, Pegg GG, Hill RA: Leptin: a review of its peripheral actions and interactions. Int J Obes Relat Metab Disord 2002, 26:1407-1433.

59. Niswender KD, Ballis B, Blevins JE, Corson MA, Schwartz MW, Baskin DG: Immunocytochemical detection of phosphatidylinositol 3-kinase activation by insulin and leptin. J Histochem Cytochem 2003, 51:275-283.

60. Figenschau $Y$, Knutsen G, Shahazeydi S, Johansen O, Sveinbjornsson B: Human articular chondrocytes express functional leptin receptors. Biochem Biophys Res Commun 2001, 287:190-197.

61. Banks AS, Davis SM, Bates SH, Myers MG: Activation of downstream signals by the long form of the leptin receptor. J Biol Chem 2000, 275:14563-14572.

62. Morrison CD, White CL, Wang Z, Lee SY, Lawrence DS, Cefalu WT, Zhang ZY, Gettys TW: Increased hypothalamic protein tyrosine phosphatase 1B contributes to leptin resistance with age. Endocrinology 2007, 148:433-440.

63. Gualillo O, Eiras S, White DW, Dieguez C, Casanueva FF: Leptin promotes the tyrosine phosphorylation of $\mathrm{SHC}$ proteins and $\mathrm{SHC}$ association with GRB2. Mol Cell Endocrinol 2002, 190:83-89.

64. Burguera B, Brunetto A, Garcia-Ocana A, Teijeiro R, Esplen J, Thomas T, Couce ME, Zhao A: Leptin increases proliferation of human steosarcoma cells through activation of $\mathrm{PI}(3)-\mathrm{K}$ and MAPK pathways. Med Sci Monit 2006, 12:BR341-349.

65. Cao Q, Mak KM, Lieber CS: Leptin enhances alpha 1(I) collagen gene expression in LX-2 human hepatic stellate cells through JAK-mediated H2O2-dependent MAPK pathways. J Cell Biochem 2006, 97:188-197. 